\title{
In vivo and in vitro catabolism of native and biologically modified LDL
}

\author{
J. Fred Nagelkerke, Louis Havekes*, Victor W.M. van Hinsbergh* and Theo J.C. van Berkel \\ Biochemistry I, Medical Faculty, Erasmus University, PO Box 1738, 3000 DR Rotterdam and *Gaubius Institute, \\ TNO, Herenstraat $5^{\mathrm{d}}$, 2313 AD Leiden, The Netherlands
}

\author{
Received 12 April 1984
}

\begin{abstract}
Incubation of human low density lipoprotein (LDL) at $37^{\circ} \mathrm{C}$ in the presence of human umbilical-vein endothelial cells (EC) causes a time-dependent shift in the charge and density of LDL. After intravenous injection into rats, native LDL is merely cleared from the circulation by Kupffer cells while EC-modified LDL is rapidly cleared by endothelial liver cells. The uptake of native LDL by Kupffer cells and ECmodified LDL by endothelial cells in vivo can be explained by the presence of two different specific receptors on these cell types. It is concluded that the liver enduthelial cells form an important protection against a possible atherogenic action of EC-modified LDL.
\end{abstract}

Human LDL Biologically modified LDL Acetylated LDL Human umbilical-vein endothelial cell Rat liver endothelial cell Rat liver Kupfer cell

\section{INTRODUCTION}

In the past decade much progress has been made in the elucidation of the mechanism by which cells endocytose low density lipoprotein (LDL). Although the importance of the receptor-mediated uptake of LDL is indicated in vitro [1] the quantitative contribution of this system to the in vivo turnover of LDL ranges from 33 to $66 \%$ [2].

Additional uptake mechanisms for LDL are therefore proposed including the involvement of a so-called scavenger receptor [3]. As a substrate for this receptor acetylated LDL (acetyl-LDL) has been used. However, the in vivo occurrence of such a chemically modified form of LDL is questionable. A more relevant biological modification of LDL can be achieved by incubation of LDL with umbilical-vein endothelial cells [4]. To assess the relative importance of the different liver cell types (parenchymal, Kupffer and endothelial cells) in the in vivo uptake of native LDL and biological-

Abbreviations: BSA, bovine serum albumin; PBS, phosphate-buffered saline ly modified LDL (EC-modified LDL), we injected the radiolabelled lipoproteins into rats and determined the cellular uptake. Additional in vitro studies were performed to determine to what extent the relative importance of the various cell types for the in vivo uptake of LDL and ECmodified LDL can be explained by the presence of specific receptors for these lipoproteins.

\section{MATERIALS AND METHODS}

LDL was isolated by ultracentrifugation and tube slicing from the blood of healthy volunteers, who had fasted overnight [5]. The LDL was immediately iodinated as in [6]. After extensive dialysis against PBS it was stabilized by addition of $10 \mathrm{mg}$ BSA per $\mathrm{ml}$ and dialysed again. Specific activity ranged from 80 to $150 \mathrm{cpm} / \mathrm{ng}$ LDL protein. The acid-soluble (non-iodine) fraction was less than $0.1 \%$.

EC-modified LDL was prepared by incubating confluent umbilical-vein endothelial cells (isolated and cultured as in [7]) in medium M-199, $10 \mathrm{~g}$ per $1 \mathrm{BSA}$ and $100 \mu \mathrm{g}{ }^{125}$ I-labelled LDL per ml 
medium. After the indicated time intervals the medium was aspirated and stored.

EC-modified LDL, non-incubated LDL and LDL incubated in the absence of cells were subjected to agarose electrophoresis as in [8]. After electrophoresis the plate was dried and subjected to autoradiography. Fig. 1 shows that the LDL incubated with umbilical-vein endothelial cells for increasing periods of time showed increasing electrophoretic mobility indicating an increase in net negative charge. The buoyant density of the LDL preparations after incubation with umbilical vein endothelial cells shifted from $1.050 \mathrm{~g} / \mathrm{ml}$ toward a mean density of $1.080 \mathrm{~g} / \mathrm{ml}$.

In some experiments LDL was acetylated with acetic anhydride as in [9].

Rat liver endothelial, Kupffer and parenchymal cells were isolated from 3-month-old male Wistar rats. For in vivo uptake studies cells were isolated 10 min after intravenous injection of the lipoprotein fractions. The entire isolation procedure was performed at a low temperature to prevent degradation of endocytosed lipoprotein during cell isolation. For in vitro studies, cells were isolated at $37^{\circ} \mathrm{C}$. Both techniques have been detailed in [10].

Incubation of cells was performed in Hams F-10 medium with the indicated amounts of lipoproteins. Determination of the amount of cellassociated lipoprotein was done as in [11]. The viability of cells before and after incubation was higher than $95 \%$ as judged by the trypan blue exclusion test. Purity of the cell preparations was checked by light microscopy: the endothelial cell preparation was more than $95 \%$ pure and the

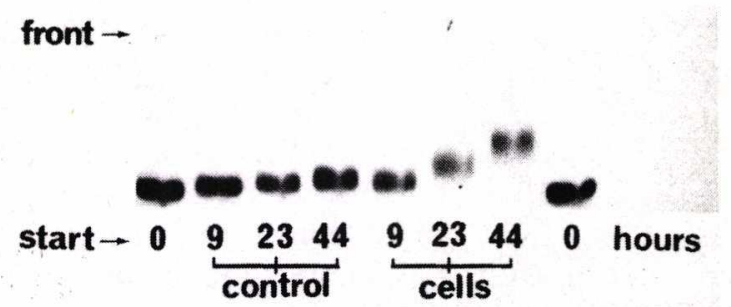

Fig.1. Agarose electrophoresis of ${ }^{125}$ I-labelled ECmodified LDL and ${ }^{125}$ I-labelled control LDL. LDL was incubated in the presence or absence of cells for increasing time periods. Electrophoresis and autoradiography were performed as in [8].
Kupffer cell preparation approx. $85 \%$, the rest being endothelial cells.

Protein was determined according to [12] with BSA as a standard.

Collagenase (type I) and BSA, fraction V, were from Sigma (St. Louis, MO), pronase (B-grade) from Calbiochem-Behring (La Jolla, CA), metrizamide from Nyegaard \& Co A/S (Oslo), Ham's F-10 from Gibco-Europe (Hoofddorp, The Netherlands), ${ }^{131} \mathrm{I}$ and ${ }^{125} \mathrm{I}$ (carrier-free) in $\mathrm{NaOH}$ from New England Nuclear (Dreieich).

\section{RESULTS AND DISCUSSION}

Native LDL and LDL incubated with umbilicalvein endothelial cells for increasing time periods were injected into rats. Subsequently serum decay and liver uptake were determined. Fig.2A shows that the serum decay of LDL is accelerated upon prolonged exposure of LDL to umbilical-vein endothelial cells.

The kinetics of liver uptake was determined by excising a liver lobule at different time intervals after injection. After weighing the lobule and counting its radioactivity the fraction of the injected dose present in the liver was calculated using the assumption that $3.75 \%$ of the total body weight is contributed by the liver [13]. It is evident that incubation of LDL for increasing periods of time with umbilical-vein endothelial cells increases the amount that becomes associated with the liver (fig.2B). Furthermore at $10 \mathrm{~min}$ after injection the amount of lipoprotein cleared from the blood is quantitatively recovered in the liver.

Determination of the cell type(s) responsible for the in vivo liver uptake was done by isolating the various liver cell types $10 \mathrm{~min}$ after injection by a cold procedure. ${ }^{125} \mathrm{I}$-labelled EC-modified LDL (incubated for $44 \mathrm{~h}$ ) was injected simultaneously with ${ }^{131}$ I-labelled native LDL. Fig. 3 shows the percentage of the injected dose of lipoprotein present in the different isolated cell fractions expressed per mg cell protein. It can be seen that the endothelial cell fraction contains much more ECmodified LDL than the Kupffer cell fraction. This becomes even more evident as the approx. $15 \%$ contamination of the Kupffer cell fraction with endothelial cells is taken into account. It can be calculated that at least 20-times more EC-modified LDL becomes associated with the endothelial cells 

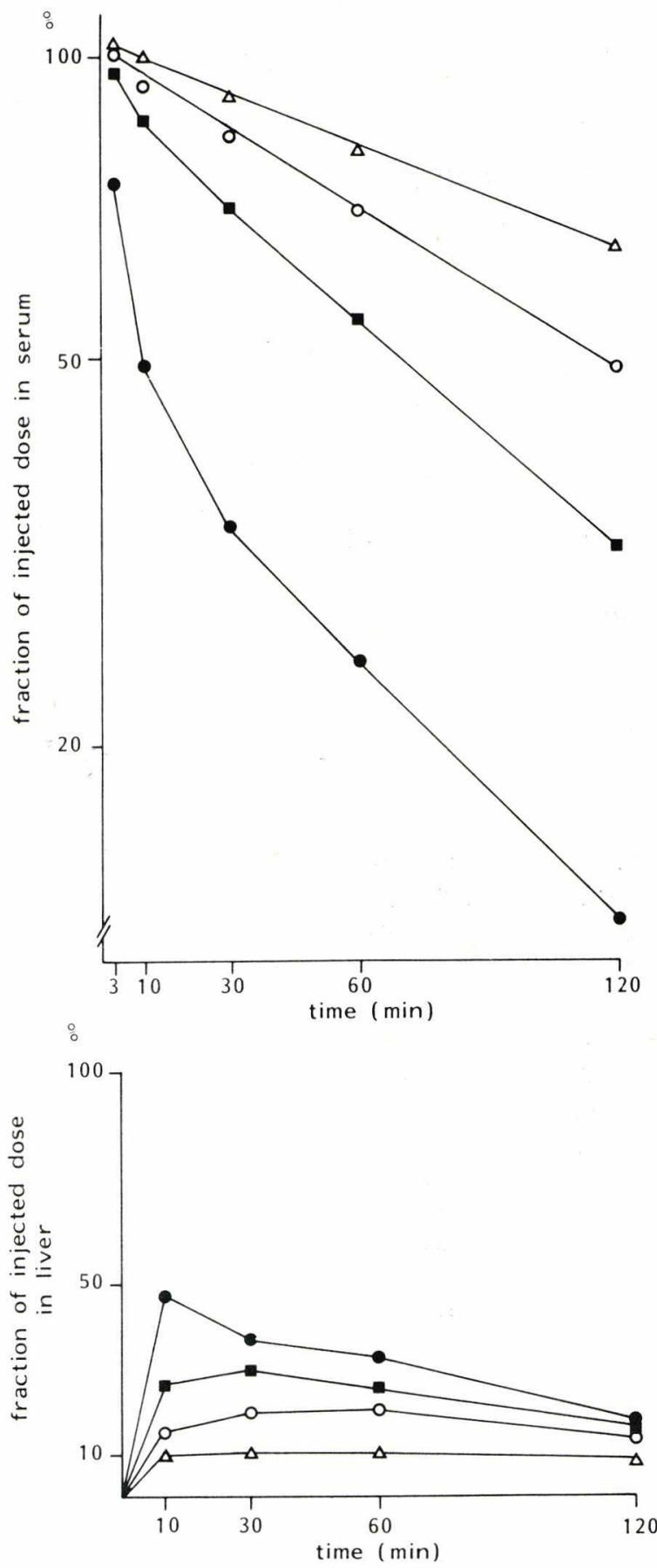

Fig.2. Serum decay (A) and liver uptake (B) after injection into rats of control $(\Delta)$ LDL and LDL incubated with umbilical-vein endothelial cell for $9(\bigcirc)$, $23(\bullet)$ or $44 \mathrm{~h}(\bullet)$. Serum values were determined in the $20000 \times g$ supernatant of blood samples. Liver uptake was determined by excising successively the different lobules of the liver followed by weighing of the lobule and counting of its radioactivity. than with Kupffer cells. Fig.3B shows the in vivo uptake of native LDL by the different liver cell types. In contrast to EC-modified LDL, the Kupffer cell fraction contains much more radioactivity per mg cell protein than do the endothelial cells.

With both EC-modified LDL and native LDL the endothelial and Kupffer cells contain approx. 30-times more radioactivity per $\mathrm{mg}$ cell protein than do the parenchymal cells. This indicates that the non-parenchymal cell types have an important function in the clearance of both these lipoproteins from the blood.

To determine the respective specificity of the interaction of EC-modified LDL and native LDL with endothelial and Kupffer cells in vitro competition experiments were performed. Freshly isolated endothelial cells were incubated with ${ }^{125}$ I-labelled EC-modified LDL and increasing amounts of unlabelled acetyl-LDL or native LDL. Fig. 4 shows that the binding and degradation of EC-modified LDL are $80 \%$ inhibited at equimolar amounts of EC-modified and acetyl-LDL. A similar experiment but with a 30 -fold excess of native LDL showed no competition (not shown). This indicates that EC-modified LDL is specifically recognized by a scavenger receptor on liver endothelial cells which also recognizes acetyl-LDL. The presence of this receptor was indicated earlier with acetyl-LDL as a substrate [10].

The specificity of the interaction of native LDL with Kupffer cells was determined by incubating this cell type with ${ }^{125}$ I-labelled native LDL and increasing amounts of unlabelled acetyl and native LDL. Fig. 5 shows that while the native LDL inhibits cell association by $50 \%$, acetyl-LDL is completely ineffective.

Because it is known that uptake of modified (denatured) proteins is likely to occur in the reticuloendothelial system (including Kupffer cells) we performed experiments to determine to what extent denaturation of a part of native human LDL during the iodination or preparation procedures could be responsible for this uptake. It was found that previous screening of LDL did not influence the serum decay or relative involvement of the different liver cell types in the liver uptake. A similar lack of screening upon liver uptake and serum decay of rat LDL was reported in [11]. Secondly, by simultaneous injection of ${ }^{125} \mathrm{I}$ labelled LDL and ${ }^{131}$ I-labelled reductively 


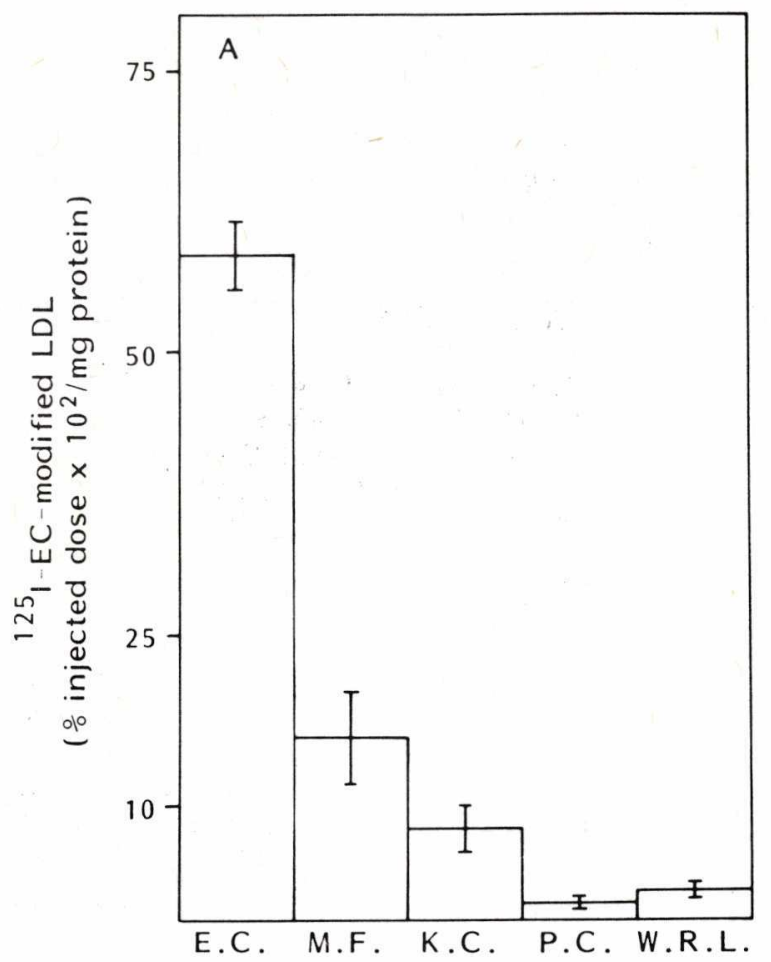

Fig. 3. In vivo uptake of ${ }^{125}$ I-labelled EC-modified LDL (incubated $44 \mathrm{~h}$ ) (A) and ${ }^{131} \mathrm{I}$-labelled native LDL (B). Both lipoproteins were injected intravenously into rats; $10 \mathrm{~min}$ later a cold liver perfusion was started. After $8 \mathrm{~min}$ perfusion a lobule was tied off and excised to determine the whole rat liver value (W.R.L.). Subsequently endothelial (E.C.), Kupffer (K.C.) and parenchymal cells (P.C.) were isolated. (M.F., mixed fraction of endothelial and Kupffer cells.) Values are expressed as percentage of injected dose per $\mathrm{mg}$ cell protein $\times 10^{2}(\mathrm{~A})$ or $\times 10^{4}(\mathrm{~B})$.

methylated LDL it was found that half of the Kupffer cell uptake can be defined as receptormediated (after reductive methylation of LDL Kupffer cell uptake was half of that obtained with native human LDL) (not shown). These results show that the Kupffer cell has a specific recognition site for LDL which plays an important role in the liver uptake of LDL.

The increased decay of LDL upon incubation with umbilical-vein endothelial cells can be adequately explained by the increased interaction of
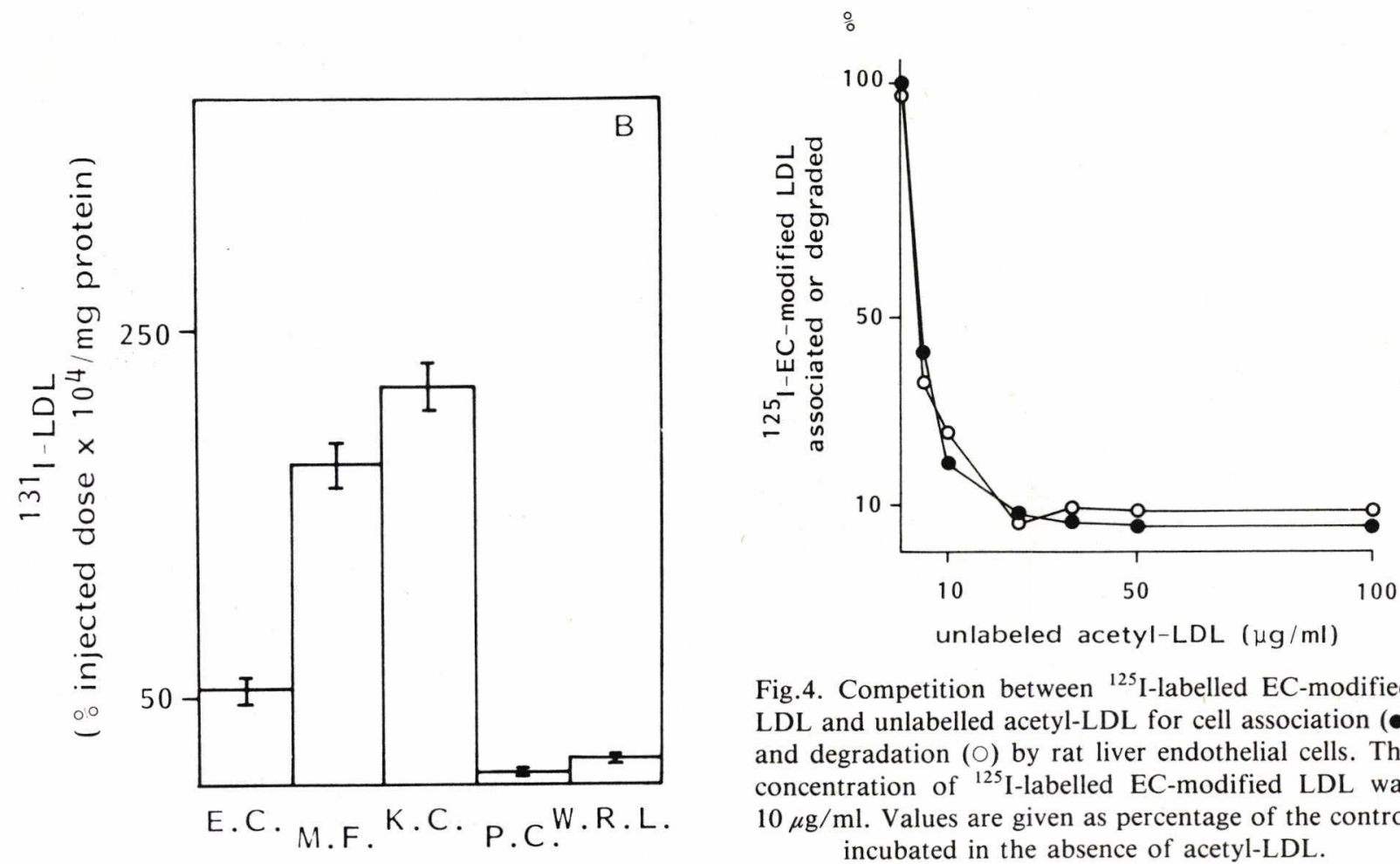

Fig.4. Competition between ${ }^{125}$ I-labelled EC-modified LDL and unlabelled acetyl-LDL for cell association (•) and degradation $(O)$ by rat liver endothelial cells. The concentration of ${ }^{125}$ I-labelled EC-modified LDL was $10 \mu \mathrm{g} / \mathrm{ml}$. Values are given as percentage of the control incubated in the absence of acetyl-LDL. 


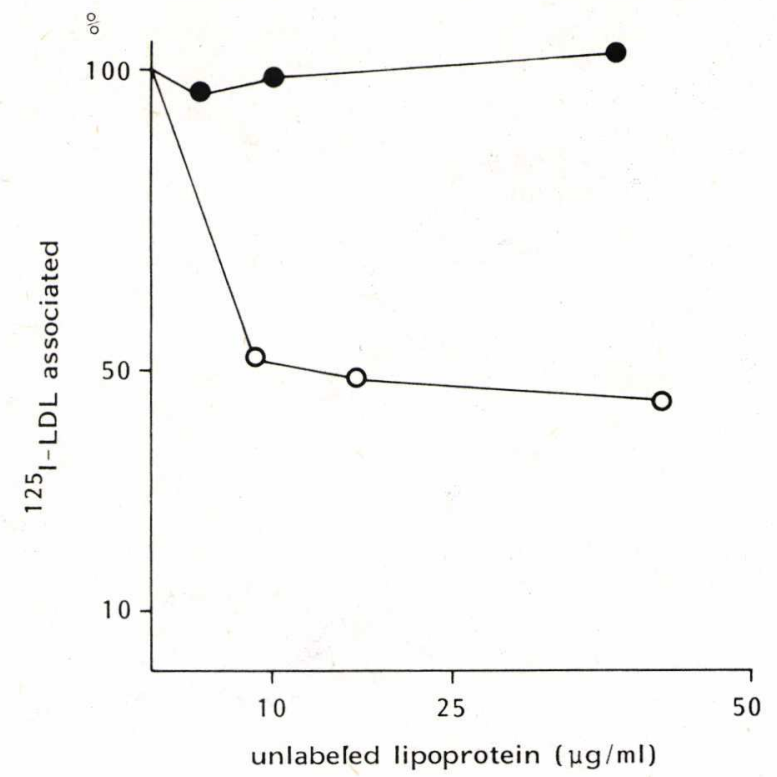

Fig.5. Competition between ${ }^{125}$ I-labelled LDL and unlabelled acetyl-LDL $(\bullet)$ or unlabelled LDL $(O)$ for cell association with rat liver Kupffer cells. The concentration of ${ }^{125}$ I-labelled LDL was $6 \mu \mathrm{g} / \mathrm{ml}$. Values are given as percentage of the control incubated solely with ${ }^{125}$ I-labelled LDL.

EC-modified LDL with the scavenger receptor on endothelial cells. Modified lipoproteins are considered as potentially atherogenic because uptake of the particles can lead to accumulation of cholesterol esters in cells of the mononuclear phagocyte system [3]. The uptake of these abnormal lipoproteins by macrophages in vivo might explain the formation of foam cells in the arterial wall [15]. If EC-modified LDL is generated in vivo and the modified LDL enters the general circulation then the liver and in particular liver endothelial cells will entrap them. In this way the occurrence of potentially atherogenic particles in the blood will be prevented.

\section{ACKNOWLEDGEMENTS}

Hille Bakkeren and Koen Barto are thanked for expert technical assistance and Martha Wieriks for the typing of the manuscript. This work was partly made possible by FUNGO grant 13.53.07 and Dutch Heart Foundation grant 82.053.

\section{REFERENCES}

[1] Goldstein, J.L. and Brown, M.S. (1977) Annu. Rev. Biochem. 46, 897-930.

[2] Brown, M.S. and Goldstein, J.L. (1979) Proc. Natl. Acad. Sci. USA 76, 3330-3337.

[3] Brown, M.S., Basu, S.K., Falck, J.R., Ho, Y.K. and Goldstein, J.L. (1980) J. Supramol. Struct. 13, 67-81.

[4] Henriksen, T., Mahoney, E.M. and Steinberg, O. (1981) Proc. Natl. Acad. Sci. USA 78, 6499-6503.

[5] Redgrave, T.G., Roberts, D.C.K. and West, C.E. (1975) Anal. Biochem. 65, 42-49.

[6] Bilheimer, D.W., Eisenberg, S. and Levy, R.I. (1972) Biochim. Biophys. Acta 260, 212-221.

[7] Van Hinsbergh, V.W.M., Havekes, L., Emeis, J.J., Van Corven, E. and Scheffer, M. (1983) Arteriosclerosis 3, 547-559.

[8] Demacker, P.N.M. (1978) Thesis, University of Nijmegen, Nijmegen, The Netherlands.

[9] Basu, S.K., Goldstein, J.L., Anderson, R.G.W. and Brown, M.S. (1976) Proc. Natl. Acad. Sci. USA 73, 3178-3182.

[10] Nagelkerke, J.F., Barto, K.P. and Van Berkel, T.J.C. (1983) J. Biol. Chem. 258, 12221-12227.

[11] Van Berkel, T.J.C., Nagelkerke, J.F. and Kruijt, J.K. (1981) FEBS Lett. 132, 61-66.

[12] Lowry, O.H., Rosebrough, N.J., Farr, A.L. and Randall, R.J. (1951) J. Biol. Chem. 93, 265-275.

[13] Blouin, A., Bolender, R.P. and Weibel, E.R. (1977) J. Cell Biol. 72, 441-455.

[14] Chao, Y., Windler, E.E., Chen, G.C. and Havel, R.J. (1979) J. Biol. Chem. 254, 11360-11366.

[15] Pitas, R.E., Innerarity, T.L. and Mahley, R.W. (1983) Arteriosclerosis 3, 1-12. 